\title{
A IMPORTÂNCIA DAS CIRCUNSTÂNCIAS JUDICIAIS PARA A EFETIVIDADE DO PRINCÍPIO CONSTITUCIONAL DA INDIVIDUALIZAÇÃO DA PENA
}

\section{THE IMPORTANCE OF JUDICIAL CIRCUMSTANCES FOR THE EFFECTIVENESS OF THE CONSTITUTIONAL PRINCIPLE OF INDIVIDUALIZATION OF THE PENALTY}

REJANE ALVES DE ARRUDA

Doutora e Mestre em Direito pela PUC/SP. Especialista em Direito Penal Econômico pela Universidade de Coimbra/IBCCrim. Advogada. Professora do Programa de Mestrado em Direitos Humanos da Universidade Federal de Mato Grosso do Sul (UFMS). Professora da Graduação e da Pós-Graduação da UFMS e da UCDB. Professora da Escola Superior da Magistratura de Mato Grosso do Sul. rejane.arruda@hotmail.com

\section{ANDRÉA FLORES}

Doutora e Mestre em Direito pela PUC/SP. Advogada. Professora do Programa de Mestrado em Direitos Humanos da Universidade Federal de Mato Grosso do Sul (UFMS). Professora da Graduação e da Pós-Graduação da UFMS e da UCDB. Professora da Escola Superior da Magistratura de Mato Grosso do Sul. andreaflores.adv@gmail.com

\section{RESUMO}

Objetivo: $O$ presente artigo tem por objetivo demonstrar a importância das circunstâncias do art. 59 do Código Penal (culpabilidade, antecedentes, conduta social, personalidade, motivos, circunstâncias e consequências do crime, 
comportamento da vítima) para a efetividade do princípio constitucional da individualização da pena, expressamente previsto no artigo 5o., inciso XLVI da Constituição de 1988. Procura-se demonstrar que a relativa indeterminação na cominação das penas, ao conferir certa margem de atuação ao magistrado, contribui para a individualização da pena, mas esta somente estará legitimada a partir da motivação das decisões judiciais.

Metodologia: $\mathrm{O}$ estudo adota o método de abordagem da revisão bibliográfica, mediante a leitura de livros, artigos científicos e a legislação.

Resultados: Concluiu-se que na individualização e na aplicação da pena, os critérios previstos no art. 59 do Código Penal são a todo momento revisitados pelo magistrado, como uma forma de adequar a sanção ao fato praticado e particularizar sua aplicação ao agente infrator e ao caso concreto.

Contribuições: $O$ estudo traz como contribuição a importância do Princípio da Individualização, calcado na liberdade, que tem sua amplitude na medida em que 0 sistema adota relativa indeterminação na cominação das penas, na proporção em que concede ao juiz certa margem de atuação. Todavia, a razoabilidade contida nesta indeterminação é imprescindível para evitar arbitrariedades.

Palavras-chave: Individualização; Pena; circunstâncias judiciais; fundamentação judicial.

\section{ABSTRACT}

Objective: To demonstrate the importance of the circumstances of Article 59 of the Criminal Code (culpability, background, social conduct, personality, motives, circumstances and consequences of the crime, victim's behavior) for the effectiveness of the constitutional principle of individualization of the penalty, expressly foreseen in Article 5, XLVI of the Constitution. Based on the foundations of the theory of crime, it is sought to demonstrate that the relative indeterminacy in the combination of penalties, by conferring a certain scope of action to the magistrate, it contributes to the individualization of the penalty, but it will only be legitimated based on the motivation of judicial decisions.

Methodology: The study adopts the method of approaching the bibliographic review, by reading books, scientific articles and legislation.

Results: The individualization and application of the penalty, the criteria foreseen in article 59 of the Penal Code are at all times revisited by the magistrate, as a way of adapting the sanction to the practiced fact and particularizing its application to the offending agent and to the case concrete. 
Contributions: The importance of the Principle of Individualization, based on freedom, which has its amplitude as the system adopts relative indeterminacy in the combination of penalties, in the proportion in which it grants the judge a certain margin of performance. However, the reasonableness contained in this indeterminacy is essential to avoid arbitrariness.

keywords: Individualization; penalty; judicial circumstances; judicial rationale.

\section{INTRODUÇÃO}

A pena bem adaptada reclama, antes de mais nada, a especialização das funções do magistrado criminal, que só mesmo com preparação intensa no amplo campo das disciplinas criminológicas poderá usar, com vantagem, o poder discricionário previsto nas disposições legais.

Certo é que tal poder encontra, nas três fases de fixação da pena, relevo especial, logo que se inicia a sua individualização, com fulcro nas circunstâncias previstas no art. 59 do Código Penal.

Tais circunstâncias são chamadas judiciais e não é à toa que possuem esta denominação. Cabe ao juiz investigá-las e mensurá-las, atribuindo-lhes a pontuação ou o valor que merecerem, segundo o caso concreto que tem em mãos.

Por outro lado, as circunstâncias legais genéricas ou específicas, além de serem previamente estipuladas e discriminadas na letra fria da lei, guardam uma maior relação com as circunstâncias objetivas do crime, não apresentando tão estreita relação com o próprio fato e a pessoa do delinquente.

Daí a preocupação deste trabalho em demonstrar que a mais concreta individualização da pena dá-se justificando o título aposto logo acima do art. 59 do Código Penal, na primeira fase da dosimetria.

Apesar de considerar-se que a individualização da pena desenvolve-se em três planos distintos (legislativo, judicial e executório), que se interpenetram e se completam, centrou-se o estudo no segundo plano, naquele em que o juiz, como figura central, assume a tarefa de tornar o Direito Penal mais concreto e menos divorciado da realidade do delinquente. 
Neste contexto, abordou-se a importância, para a consecução da individualização da pena, da relativa indeterminação do sistema legal, sem olvidar da motivação como instrumento apto a conferir legitimidade ao arbítrio judicial.

De imediato, situando o tema proposto, são apontadas diversas formas como as circunstâncias judiciais, em razão de suas particularidades, distinguem-se como instrumentos e critérios de individualização da pena.

Cumpre lembrar que as circunstâncias enumeradas no art. 59 do Código Penal exercem influência na aplicação de outros institutos do Direito Penal, fato que, além de incentivar a continuidade de sua reflexão, enseja, para o profissional do Direito, a compreensão de sua importância.

\section{INDIVIDUALIZAÇÃO LEGISLATIVA, JUDICIAL E EXECUTÓRIA}

Diz-se no Direito Penal que a individualização da pena começa a realizar-se no momento da confecção da lei impessoal e abstrata, no instante em que o legislador, afastado da realidade do crime, estabelece genericamente as figuras delituosas, determinando especificamente suas penas e as circunstâncias que podem ocasionar seu aumento ou diminuição.

Segundo Aníbal Bruno, nesta individualização dita legal ou legislativa, temse em vista o valor que a ordem de Direito atribui ao bem jurídico que se pretende proteger, adapta-se a natureza e quantidade da pena ao valor do bem objeto da proteção legal (BRUNO, 1966, p.90).

Garraud chega a distinguir culpabilidade absoluta ou legal de culpabilidade individual ou judiciária. A primeira diz respeito à culpabilidade abstrata ou objetiva tomada pelo legislador, enquanto que a segunda alude à culpabilidade concreta ou subjetiva aferida pelo juiz (GARRAUD, 1926, p.399). E não poderia ser diferente, pois a definição legal contém apenas os extremos essenciais da ação punível, de sorte que a gravidade do fato não pode ser somente deles deduzida, mas também e 
principalmente de condições particulares que variam de uma infração penal para a outra e imprimem, a cada uma delas, a sua fisionomia particular.

Até porque se verifica que não é possível ao legislador promover a efetiva individualização da pena porque, para ele, a realidade do crime não é o fato concreto, mas o tipo penal abstrato, motivo pelo qual acaba por admitir e assegurar largas possibilidades à individualização judicial (BRUNO, 1966, p.104).

Assim, resta ao aplicador da lei, ou seja, ao juiz, a tarefa de resolver, no caso concreto, a questão que o legislador teve que resolver genericamente. Nesse sentido, conclui Liszt: "o legislador antes socializa que individualiza, o juiz individualiza a pena, socialmente."1

Para esta tarefa, Ferri sugere os passos que devem ser seguidos em cada julgamento penal para chegar-se, verdadeiramente, com garantia dos direitos individuais e sociais, à imposição de uma pena: $1^{1} \stackrel{0}{ }$. - verificação do cometimento do fato (prova genérica); $2^{\circ}$. - verificação da tipicidade e antijuridicidade (prova jurídica); $3^{\circ}$. - verificação da autoria (prova específica); 4‥ - verificação das condições pessoais e de ambiente em que foi cometido o crime (prova psicológica) e, portanto, se o agente é ou não moralmente responsável; 5 ‥ - verificação do grau da sanção repressiva posta pela lei que deve ser estabelecida contra o réu (conclusão judicial) (FERRI, 1999, p.329).

Contudo, por constituir a pena dosada a recomendação judicial para a reprovação e prevenção da infração penal praticada, necessárias tornam-se a sua concretização e a sua execução. Fala-se, então, de individualização executória ou administrativa, ficando seu trato reservado ao Direito Penitenciário.

Nesta última instância de individualização é que as finalidades atribuídas às penas podem, de fato, ser alcançadas. De nada vale estabelecer, em teoria, certos

\footnotetext{
${ }^{1}$ Liszt. Tratado de Derecho Penal, p. 338 a 369: "El Juez debe fijar la pena para cada delito dado; debe resolver, enel caso concreto, La cuestión que el legislador tuvo que resolver en general. (...) Ni al Juez es aje na la consideración social, em La aplicación específica, concreta, de la pena, ni al legislador La consideración individual, em La aplicación abstracta, genérica. Mas suposición es extrema, entre lãs variables de lagrancuestión. El legislador, antes socializa que individualiza; el Juez individualiza la pena, socialmente. Aquélve al delincuente em La sociedad, desde La ley; éste a la socieda de nel delincuente, desde lã sentencia."
} 
critérios e atribuir à pena determinada tarefa se, depois, no momento da execução, realiza-se verdadeira traição.

É por tal razão que o legislador penal subtraiu ao arbítrio da administração a totalidade da missão de execução da pena, determinando regras de direito que devem ser observadas. Em nossa legislação, estas regras encontram-se, preferencialmente, na Lei de Execução Penal.

\section{A INDETERMINAÇÃO RELATIVA DAS PENAS}

Constata-se que a individualização judicial da pena envolve um postulado prático: a liberdade judicial. Liberdade de convencimento, na apreciação das provas, na disposição de sua sentença e na graduação da pena. Daí a impossibilidade do legislador prescrever uma sanção rígida e invariável.

Com efeito, se existe a necessidade da individualização da pena que, segundo Nelson Hungria, significa retribuir o mal concreto do crime, com o mal concreto da pena, na concreta personalidade do criminoso (LUISI, 1991, p.37) ${ }^{2}$, e esta individualização não se completa a nível legislativo, a sanctio juris da norma penal incriminadora deve conter certo grau de indeterminação, de forma a permitir o exercício do chamado arbitrium judicis.

Nem determinação absoluta, portanto, e nem absoluta indeterminação. A pena absolutamente determinada impediria o seu ajustamento às infinitas variedades de fatos e a seus agentes, segundo a realidade de cada caso concreto. Já a pena absolutamente indeterminada deixaria demasiado arbítrio ao julgador com prejuízo da necessária garantia dos direitos individuais (BRUNO, 1966, p.102).

Este sistema opõe-se ao chamado sistema de penas fixas, que vigorou no Código do Império $^{3}$, nas quais o legislador não outorgava ao juiz a faculdade individualizadora.

\footnotetext{
${ }^{2}$ Neste caso, aceita-se, como inegável, a finalidade retributiva da pena.

3 Nesse sentido, o artigo 63 do Código de Império: "Quando este Codigo não impõe pena determinada, fixando somente o máximo e o mínimo, considerar-se-hão três gráos nos crimes, com
} 
Ao afastar-se de qualquer extremismo e optar por relativa indeterminação, o Código Penal reconhece ao juiz uma parcela de discricionariedade, não se esquecendo de restringir a prepotência estatal através de critérios previamente delimitados em lei.

É exatamente por isso que a fase da aplicação da pena, além de ser motivada, apresenta uma complexidade de detalhes cujo desacato corresponderá a um julgamento eivado de ilegalidade, lesivo ao direito fundamental da individualização da pena (ROSA, 1995, p. 246).

\section{A MOTIVAÇÃO COMO GARANTIANA INDIVIDUALIZAÇÃO DA PENA}

Sendo impossível a admissão de uma fiel exatidão na proporção entre o crime e a sanção, o Princípio da Individualização da Pena foi consagrado na Constituição Federal de 1988, em seu artigo 5‥, inciso XLVI.

Em razão dessa realidade, não deve existir automatismo na aplicação da pena, de sorte a predominar, no esquema legislativo de cominação de penas, a referida abertura que viabilize a discricionariedade do magistrado.

Ao comentar sobre a tarefa que coube ao juiz, Bettiol lembra que ela se fez sentir com o aparecimento da ideia naturalista da prevenção especial, que insistia sobre a necessidade de adaptação da sanção à personalidade criminológica do agente. Segundo ele, o que importa é a periculosidade do réu, de modo que o magistrado deve gozar de ampla liberdade de apreciação e de julgamento, para que a medida não se enrijeça num esquema que não realiza finalidade alguma (BETTIOL, 1966, p.154).

Adverte-se, todavia, que a garantia do Princípio da Individualização encontra-se na motivação. Se, por um lado, concedeu-se liberdade de atuação ao

attenção ás suas circunstancias aggravantes ou attenuantes, sendo o maximo o de maior gravidade, á que se imporá o maximo da pena; o minimo, o da menor gravidade, á que se imporá a pena minima; o médio o que fica entre o maximo e o minimo, á que se imporá a pena no termo médio entre os dous extremos dados". 
juiz para concretizar o jus puniendi, por outro, exigiu-se que prestasse contas de sua decisão, elencando os motivos e as razões que a ensejaram. Fala-se, por isso, em discricionariedade circunscrita.

A obrigatoriedade de motivação das decisões judiciais está expressamente prevista na Constituição Federal de 1988. Primeiro o art. 93, inciso IX, prescreve que

\begin{abstract}
[...] todos os julgamentos dos órgãos do Poder Judiciário serão públicos, e fundamentadas todas as decisões, sob pena de nulidade",e depois o artigo $5^{\circ}$, inciso LXVI, ao se referir às prisões, prevê que "ninguém será preso senão em flagrante delito ou por ordem escrita e fundamentada de autoridade judiciária competente[...].
\end{abstract}

Segundo Antônio Magalhães Gomes Filho, a motivação das decisões judiciais adquire uma conotação que transcende o âmbito do próprio processo para situar-se no plano mais elevado da política, caracterizando-se como o instrumento mais adequado ao controle sobre a forma pela qual se exerce a função judiciária (MAGALHÃES, 1988, p.60).

Segundo o autor, nesse plano político, a exigência de motivação representa: a) uma forma de participação do povo na administração da justiça, que se realiza pelo controle democrático a posteriori sobre os fundamentos do ato do juiz; b) um modo de vincular os pronunciamentos jurisdicionais à legalidade, uma vez que juízos mais complexos demandam não somente a escolha da regra, mas também a sua interpretação e, ainda, a verificação de seu conteúdo como os preceitos maiores da lei fundamental; c) um instrumento de garantia de efetividade dos direitos e garantias fundamentais, eis que a motivação das decisões judiciais serve, de um lado, para verificar o acompanhamento do raciocínio desenvolvido pelo juiz para chegar a um eventual provimento restritivo daqueles direitos e, por outro, para constatar se a decisão aplicou validamente as normas que permitiam a restrição e se foi apreciado, de maneira correta, o contexto fático que a autorizava. ${ }^{4}$

É pela motivação da sentença que se pode apreciar, conforme ressaltou Dias Ferreira, se o juiz formou a sua convicção por motivos legítimos e não por puro

${ }^{4}$ Código de Processo Civil, p. 171, conf. Marques, 1997, p. 328. 
arbítrio. ${ }^{5}$ Ademais, a defesa e a acusação têm o direito de saber por quais caminhos e com quais fundamentos o juiz chegou à fixação da pena definitiva. Escamotear tais caminhos é cercear a defesa ou desarmar a acusação. É, principalmente, impossibilitar o ataque lógico ao julgado objeto de recurso (SHECAIRA; et. al., 1995, p.176).

Segundo Aury Lopes Júnior, para o controle da eficácia do contraditório e do direito de defesa, bem como de que existe prova suficiente para sepultar a presunção de inocência, é fundamental que as decisões judiciais (sentenças e decisões interlocutórias) estejam motivadas (LOPES JR, 2017, p.868).

Desse modo, a motivação contribui para a legitimidade do Princípio da Individualização, enquanto realidade na atuação judicial, contribuindo para a efetividade do processo, na medida em que permite a persuasão do vencido e o acatamento sem recurso da sentença" (CRUZ, 1991, p.397).

Segundo Ferrajoli, "el modelo penal garantista equivale a un sistema de minimización del poder y de maximización del saber judicial, en cuanto condiciona la validez de las decisiones a la verdad, empírica y lógicamente controlable, de sus motivaciones" (FERRAJOLI, 1997, p.22).

Logo, revela-se a salutar importância do artigo 381, inciso III, do Código de Processo Penal, ao impor, como requisito da sentença, os motivos de fato e de direito em que se fundar a decisão.

\section{AS CIRCUNSTANCIAS JUDICIAIS COMO CRITÉRIOS PRIMORDIAIS DE INDIVIDUALIZÇÃO DA PENA}

É possível afirmar que a individualização e consequente aplicação da pena ancora-se essencialmente nos critérios fixados no art. 59 do Código Penal.

Os elementos ali mencionados constituem diretrizes que indicam 0 procedimento a ser adotado na tarefa individualizadora da pena-base e, por

${ }^{5}$ Código de Processo Civil, p. 171, conf. Marques, 1997, p. 328. 
considerarem especialmente a pessoa do delinquente, facilitam a concreção do Princípio da Individualização da pena.

Em que pese as circunstâncias judiciais previstas no art. 59 do Código Penal - culpabilidade, antecedentes, conduta social e personalidade - indicarem, num primeiro olhar, uma culpabilidade do agente, constata-se que na tarefa de individualização da pena o juiz atem-se, em especial, à culpabilidade do ato.

De fato, enquanto a culpabilidade do autor pune o agente pelo que ele é, a culpabilidade do ato impõe-Ihe uma punição pelo que fez. E não poderia ser diferente, uma vez que a admissibilidade da punição do agente por sua conduta de vida resultaria fatalmente numa afronta ao Princípio da Legalidade, resultando numa reprovação por condutas anteriores consideradas por vezes atípicas.

Em discurso proferido a sete de dezembro de 1940 no Tribunal de Aplicação do Distrito Federal, o Sr. Ministro da Justiça, salientou que:

[...] o traço que situa melhor o Código Penal no domínio da Justiça é o grande crédito que ele abre à capacidade intelectual e moral do juiz, confiando à retidão da sua inteligência e do seu caráter todo o mecanismo repressivo e preventivo da criminalidade (PONTES, 1942, p.97).

Nesta tarefa de individualização, consoante ressaltou Aníbal Bruno, o juiz tem importante missão. Ao servir-se do artigo 59 do Código Penal que admite um extenso arbítrio no sentido de ajustar a pena à pessoa do delinquente, tem de satisfazer duas exigências de segurança e de justiça - a do interesse público de ordem e equilíbrio social - e a do destino do homem violador da norma que se vai cumprir por decisão sua (BRUNO, 1966, p.92).

Adverte-se, entretanto, que o exercício de tal incumbência somente ocorrerá se o sistema de aplicação de penas dispuser da relativa indeterminação já comentada, ou seja, de certa margem de atuação que permita ao juiz, de acordo com as particularidades do caso sub judice, promover a adequação da sanção.

Com efeito, basta que se recorde que a primeira reação do Direito Penal ao arbítrio judicial dos tempos medievais foi a adoção da pena fixa, representando o "mal justo" na exata medida do "mal injusto" praticado pelo delinquente. 
$\mathrm{Na}$ verdade, pelo que já foi dito, percebe-se que a pena absolutamente indeterminada deixa demasiado arbítrio ao julgador, com sérios prejuízos aos direitos fundamentais do indivíduo, além de enfraquecer a função intimidativa do Direito Penal. Igualmente a pena absolutamente determinada impede o seu ajustamento ao fato e ao agente, diante da realidade concreta.

Ao longo da história, essa constatação determinou a evolução para uma indeterminação relativa. Abriu-se, com o Código Penal francês de 1810, um grande crédito à livre apreciação da prova pelo juiz, estabelecendo limites mínimo e máximo, dentre os quais pode variar a mensuração da pena (BITENCOURT, 1996, p.497-498).

Mas não é somente a indeterminação absoluta ou relativa da pena que dá azo a controvérsias. Mesmo que não se tenha um modelo rígido de aplicação de penas, de sorte a conferir liberdade de apreciação ao magistrado, os limites mínimos e máximos, que possam vir a ser estipulados no momento da cominação, sofrem a influência mais ou menos liberal de todo o sistema legal.

A lei do Estado de Nova York, por exemplo, estabelece parâmetros extremamente largos para vários crimes - 1 a 25 anos para roubo a banco, 1 e 1/2 a 15 anos para roubo de 1 o grau (CRUZ, 1991, p.395).

Neste contexto, torna-se oportuna a lembrança de Everardo da Cunha Luna, para quem a aproximação dos mínimos e máximos gera duas vantagens: a) evitamse penas muito curtas (mínimo) e b) penas demasiado longas (máximo) (LUNA, 1975, p.266).

Certo é que a técnica legislativa se excede em qualidade quando estabelece limites mais estreitos para a dosagem da pena. Quando a letra fria da lei demonstra abstratamente sua preocupação com a proporcionalidade que deve existir entre a infração e sua repressão e empreende, desde logo, a individualização legal de que se falou, facilitando a posterior atividade judicial.

O juiz, ao ser chamado a promover a dosagem da pena, conta com a liberdade que the fora concedida e com a legitimidade de seu grau. Contudo, ao 
sentir-se passível de extremismos e radicalismos, tranquiliza-se no instante em que sua atividade é pautada por uma lei que também é legítima.

\subsection{CIRCUNSTÂNCIAS JUDICIAIS E SISTEMA TRIFÁSICO}

Individualizar significa ajustar a pena ao agente, segundo suas próprias características e segundo aquelas que particularizam o fato delituoso cometido.

A partir dessa concepção, pode-se concluir que a individualização da pena está compreendida nas três fases de sua aplicação, de modo que cada particularidade influi no seu ajuste, seja porque está prevista como causa de aumento ou de diminuição, circunstância atenuante ou agravante, ou mera circunstância judicial.

Justificando tal assertiva, recorre-se a um fato hipotético em que o agente pratica determinada conduta criminosa, impelido por motivo de relevante valor moral. Nesse contexto, receberá uma sanção individualizada, segundo a qualidade do móvel de sua ação. Tratando-se a conduta típica de homicídio ou de lesões corporais, será aquele elemento uma causa de diminuição de pena. Dizendo respeito a um delito de violação de correspondência, será tido, no máximo, como circunstância atenuante. E se, porventura, não fosse previsto como tal, seria tomado na fixação da pena-base na primeira fase da dosimetria.

A propósito, adverte-se que, havendo coincidência de circunstâncias, seu reconhecimento respeita uma ordem de consideração estabelecida segundo o peso da reprovabilidade da conduta: qualificadora, causa de aumento, circunstância agravante genérica, circunstância judicial. A solução constitui decorrência lógica e procura evitar o chamado bis in idem.

É fundamental, portanto, ter-se em conta uma regra básica: não se pode desvalorar duplamente, e, muito menos, triplamente, uma mesma circunstância, isto é, existe uma proibição de desvalorização plural de circunstâncias (ZAFFARONIET; et. al., 1997, p.831). 
Tal regra é encontrada no art. 61, relativa às agravantes genéricas, "que sempre agravam a pena, quando não constituem ou qualificam o crime", devendo ser estendida a qualquer característica que faça ou não parte do tipo.

Contudo, mesmo reconhecendo que o Princípio da Individualização transpareça durante todo o método trifásico de aplicação da pena, observa-se que é no primeiro estágio que o mesmo ganha primazia, é nas circunstâncias judiciais que se apresenta mais incutido.

Precipuamente, observa-se que o art. 59 do Código Penal compõe-se de uma gama de circunstâncias que, conjuntamente, envolvem autor, vítima e fato delituoso, permitindo extensa margem de atuação judicial.

Elementos essenciais para o processo de individualização, como as condições antropológicas e o grau de culpa do agente, são aferidos nesta fase e a partir daquelas circunstâncias. O juiz, além de poder atribuir-Ihes um quantum que entenda conveniente, poderá considerá-las favorável ou desfavoravelmente ao autor do fato, segundo sua investigação no curso da instrução.

A sensação de completude, de que desfrutam as circunstâncias judiciais, torna-se ainda mais latente quando se percebe, ante a inexistência de agravantes ou atenuantes, causas de aumento ou de diminuição, que a pena-base pode converterse em pena definitiva.

$\mathrm{Na}$ análise das circunstâncias judiciais, pode o magistrado privilegiar algumas consoante a natureza do crime sub judice. Assim, nos crimes contra a dignidade sexual, tende a sopesar com maior cautela o comportamento da vítima, nos crimes de perigo, a culpabilidade do agente, nos crimes contra o patrimônio, as circunstâncias do crime e nos crimes contra a vida, os motivos que levaram o agente a praticá-lo, desde que não atuem como qualificadoras ou minorantes.

Tal raciocínio vem expresso também no art.42 da Lei ㄲo. 11.343/2006 ao determinar que o magistrado, na fixação da pena-base dos crimes da Lei de Drogas, deve levar em consideração preponderantemente a natureza e a quantidade da substância ou do produto, a personalidade e a conduta social do agente. 
Todavia, recorda-se que o Direito Penal tem como postulado o já mencionado Princípio da Legalidade, segundo o qual "não há crime sem lei anterior que o defina, nem pena sem prévia cominação legal". A adoção deste princípio implica em exigir-se que, além dos elementos essenciais do crime, aqueles que são acidentais, relacionados ora com o tipo penal, com a antijuridicidade, com a culpabilidade ou com a punibilidade da conduta, devam estar previstos tipicamente no modelo circunstanciado da Parte Especial ou da Parte Geral.

Ainda que se encontrem fora do tipo penal incriminador, tais aspectos encarnam um valor caro ao Direito, cuja positividade quer o Estado prestigiar por intermédio de comandos ou proibições, sob ameaça de pena" (BITENCOURT, 1996, p.57).

Por conseguinte, tomando o Princípio da Legalidade como um instrumento criado pelo Estado para impedir, segundo as palavras de Cernicchiaro, "que o Executivo e o Judiciário possam, do gênero, definir a espécie," (CERNICCHIARO, 1995, p.22) a expressa enumeração de agravantes e atenuantes e de causas de aumento e diminuição implicam na obrigatoriedade de sua aplicação.

Daí ratificar-se o entendimento, já identificado, de que o juiz tem maior liberdade na primeira etapa da dosimetria da pena, tendo oportunidade de questionar, de modo favorável ou não, as condições antropológicas do agente, seu grau de culpa, etc. Tanto assim que se distinguem duas espécies de circunstâncias: as "judiciais" e as "legais".

No sistema trifásico, embora a primeira e segunda fase tenham por semelhança a indeterminação legislativa do quantum de valoração a ser dada pelo magistrado, ambas se diferem na margem de discricionariedade do próprio reconhecimento. Enquanto na primeira quadra serão analisadas as ditas circunstâncias judiciais, ou seja, em que o juiz reconhecerá, por exemplo, quais os motivos do crime que consideram favoráveis ou desfavoráveis ao réu, na segunda, levará em consideração as circunstâncias legais agravantes ou atenuantes nas quais o legislador arrolou quais os motivos devem ser considerados como agravante 
(torpe ou fútil) e quais os que serão reconhecidos como atenuantes (relevante valor moral ou social), limitando a margem de discricionariedade do magistrado.

Neste sentido, Luis Luisi reconheceu que nesta atividade do julgador está habitualmente presente um coeficiente criador, e mesmo irracional, no qual, inclusive inconscientemente, projetam-se a personalidade e as concepções da vida e do mundo do juiz. Mas, sob outro prisma, lembrou-se da lição de Emílio Dolcini, segundo a qual não existe uma irremediável e insuperável antinomia entre o caráter criativo e o caráter vinculado da discricionariedade, pois este componente emocional e imponderável pode atuar na opção do juiz determinando-lhe apenas uma escolha dentre as alternativas explícitas ou implícitas contidas na lei (LUISI, 1991, p.39).

Daí a exigência de motivação do conteúdo decisório, da demonstração clara do raciocínio que foi formado para dosar a pena, como forma de controle, ao lado do Princípio da Legalidade, da discricionariedade judicial.

Assim, todas as operações realizadas na dosagem da pena, que não se resumem a uma simples operação aritmética, devem ser devidamente fundamentadas, esclarecendo o juiz a valoração dada a cada circunstância analisada, permitindo às partes a compreensão dos critérios utilizados.

\subsection{CIRCUNSTÂNCIAS JUDICIAIS E APLICAÇÃO DA PENA}

No art. 59 do Código Penal, a concretude do Princípio da Individualização da Pena não se cinge à determinação circunstanciada da pena-base a partir dos fatores ali enumerados.

Ora, ainda no corpo daquele dispositivo legal, o legislador deixou, a critério do juiz, a escolha da qualidade da pena dentre as cominadas e, em se tratando de pena privativa de liberdade, seu regime inicial de cumprimento e o exame de sua possível substituição. 


\subsubsection{Escolha da Modalidade de Pena}

Julgando procedente a pretensão punitiva, cabe ao juiz a escolha da pena a ser cumprida pelo agente infrator.

Apesar de a Constituição prever cinco modalidades de penas, o Código Penal adotou apenas três para os crimes: as privativas de liberdade (reclusão e detenção), a pecuniária (multa) e as restritivas de direitos, sendo que estas últimas, apesar de autônomas, em regra, não são cominadas aos crimes em espécie e servem apenas para substituir as primeiras quando presentes os requisitos legais.

Cominadas, portanto, são, em regra, as privativas de liberdade e a multa, ora alternadamente, ora cumulativamente, ora isoladamente.

Como resta claro, a liberdade judicial situa-se apenas na primeira hipótese, quando pode optar por uma pena privativa de liberdade ou pela pena pecuniária.

O Código Penal não previu um critério especial para a promoção de tal escolha, porém, o fato de prescrever tal tarefa no corpo do artigo 59, justamente um dispositivo legal que traz expressas as finalidades da pena, pressupõe que a opção deverá recair na modalidade de pena que atenda à reprovação e prevenção do crime, consoante sua necessidade e suficiência.

\subsubsection{Fixação da Pena-Base}

Segundo o art. 59 do Código Penal, as circunstâncias judiciais têm como finalidade servir de critérios para a fixação da pena-base.

Esta se refere à pena que serve de ponto de partida para o cálculo da graduação da sanção final a ser imposta ao agente. Sobre ela se apoiará eventualmente agravantes e/ou atenuantes, majorantes e/ou minorantes, consoante às particularidades do caso concreto.

Por tal razão, diz-se que sua origem advém de uma necessidade prática e vinculada à aplicação do sistema. Ela se impõe como fundamento, ponto de partida de uma operação (FARIA, 1959, p.18). 
Diverge a doutrina quanto à identificação deste ponto de partida. Para Nelson Hungria, a fixação da pena deve emanar de um termo médio, a ser calculado entre o máximo e o mínimo cominados abstratamente pelo legislador (FERREIRA, 1998, p.526).

Os demais doutrinadores que com ele são concordes, ressaltam que tal entendimento preserva a função das circunstâncias atenuantes, uma vez que, sendo a pena-base dada no mínimo legal, estas não mais poderiam ser aplicadas.

Todavia, observa-se que o legislador não dispõe, em momento algum, qual o método a ser utilizado, pelo que o juiz, ao ser levado a fixá-lo, pode vir a prejudicar o réu quando inexistirem circunstâncias legais a serem consideradas.

Talvez por este motivo é que alguns autores pactuam da tese de que as atenuantes podem trazer a pena aquém do mínimo legal.

Certo é que o juiz, ao fixar a pena-base, deve esclarecer a quantidade de pena que utilizou em relação a cada uma das circunstâncias judiciais. Despicienda torna-se tal fundamentação quando restringir-se à pena mínima cominada.

Atualmente, o posicionamento que ganha maior relevo quanto ao quantum de cada circunstância judicial é aquele que determina que seja feita a diminuição da pena mínima da pena máxima e o resultado seja dividido por oito, número de circunstâncias judiciais elencadas no art. 59. Daí retira-se o limite máximo de valoração de cada circunstância judicial que viesse a ser considerada em desfavor do réu. Num delito de roubo simples, por exemplo, em que a pena cominada é de reclusão de 4 a 10 anos, cada circunstância judicial poderia valer no máximo 9 meses, resultado deste cálculo aritmético (10-4=6 anos, 6 anos corresponde a 72 meses, que dividido por 8 , resulta em 9 meses).

\subsubsection{Fixação do Regime Inicial}

No Código Penal, as penas privativas de liberdade dividem-se em reclusão e detenção. 
A primeira, cominada aos delitos mais graves, deve ser cumprida em regime fechado, semiaberto ou aberto. Por sua vez, a segunda, em regime semiaberto ou aberto, salvo a necessidade de transferência para regime fechado.

Embora 0 art. 59 do Código Penal determine a incumbência do juiz de estabelecer o regime de cumprimento da pena privativa de liberdade, observa-se que tal providência só pode ser tomada após percorrer-se todo o sistema trifásico, ou seja, apenas quando ficar definitivamente delimitada a pena a ser aplicada.

É o art. 33 do Código Penal que regula os critérios a serem utilizados para a fixação do regime inicial de cumprimento de pena, mas é no seu $\S 3^{\circ}$. que se encontra a participação das circunstâncias judiciais.

Surge, então, a dúvida em saber quais os critérios a serem utilizados: se o primeiro, baseado na quantidade de pena dada, ou o segundo, segundo as circunstâncias judiciais.

Para sanar a antinomia aparente, resta considerar que o artigo 59 será apreciado somente quando se tratar de réu condenado à pena que preveja regime semiaberto ou aberto, mas cujas circunstâncias judiciais recomendem regime mais ou menos rigoroso.

Portanto, se a pena concreta imposta ao réu lhe der direito a cumprimento da pena no regime aberto, a escolha de regime mais rigoroso terá que ser fundamentada na reincidência e nas circunstâncias judiciais desfavoráveis. Mesmo raciocínio se dá quando a pena der direito ao regime semiaberto e o juiz fixar o regime fechado.

\subsubsection{Substituição de Penas}

Escolhida e dosada a pena privativa de liberdade, passa o juiz a apreciar a viabilidade de substituí-la por penas restritivas de direitos ou por multa.

$\mathrm{O}$ art. 44 do Código Penal prevê as hipóteses de cabimento da substituição das penas privativas de liberdade por restritivas de direitos. 
Desses requisitos, o que interessa de forma mais imediata é o previsto no inciso III, já que faz alusão à seis das oito condições judiciais previstas no art. 59 do Código Penal, excluindo apenas as consequências do crime e o comportamento da vítima.

A inclusão daquelas circunstâncias judiciais, como condição para deferimento da substituição pelas penas restritivas de direitos, atende à coerência sistemática do Código Penal ao ter enumerado, em seu art. 59, inciso IV, tal providência judicial. Ademais, deixa claro que as circunstâncias judiciais são tomadas, novamente, como critérios dentro da legislação penal.

Nesse sentido, reconheceu Luiz Flávio Gomes (1999, p.116) que, mais uma vez, o legislador deixou por conta dos operadores jurídicos a tarefa de individualizar o instituto alternativo da substituição em cada caso concreto.

Por outro lado, a importância daquelas circunstâncias terem sido eleitas, como elementos informadores da conveniência ou não da aludida substituição, aumenta ao recordar-se que os incisos I, II e III são exigidos simultaneamente. Uma vez preenchidos todos, pode-se falar em direito público subjetivo do acusado à substituição da pena.

É justamente a partir desses critérios, cuja análise fica ao encargo do magistrado, que poderá existir uma valoração, por exemplo, sobre a concessão ou não da substituição para o delito de tráfico privilegiado de drogas.

Os argumentos acima utilizados servem também para a substituição da pena privativa de liberdade pela multa, uma vez que 0 art. $60, \S 2^{\circ}$., refere-se ao inciso III do art. 44 do Código Penal.

Enfim, cumpre notar que seis, dos oito fatores contidos no art. 59, foram numerados como critérios para a concessão do Sursis (art. 77, III), da Suspensão Condicional do Processo (art. 89, Lei no 9.099/1995) e para o aumento de pena no crime continuado qualificado (art. 71, parágrafo único).

Do mesmo modo, insiste Zaffaroni que, muito embora o art. 68 disponha que "a pena-base será fixada atendendo ao critério do art. 59", percebe-se que tal 
prescrição legal cumpre uma função de indicar regras que vão além da pena-base (ZAFFARONI; et. al., 1997, p.832). ${ }^{6}$

\section{CONSIDERAÇÕES FINAIS}

Procurando trilhar o caminho traçado de demonstrar a importância das circunstâncias judiciais para a efetividade do princípio da individualização da pena, observou-se, em primeira mão, que a individualização da pena, no processo que vai do nível legislativo até o administrativo, sofre uma evolução de concretude, culminando na fase dita executória. Centrado o estudo na atividade judicial, percebeu-se sua importância para tornar concreta a pena abstratamente cominada, sob a responsabilidade de defini-la um tanto quanto viável para ser executada e atingir os fins a que se destina.

Calcado na liberdade, constatou-se que o Princípio da Individualização tem sua amplitude na medida em que o sistema adota relativa indeterminação na cominação das penas, na proporção em que concede ao juiz certa margem de atuação. Todavia, a razoabilidade contida nesta indeterminação é imprescindível para evitar arbitrariedades, pelo que se fala de discricionariedade circunscrita.

Como num sistema de freios e contrapesos, uma vez concedido espaço para a tarefa do aplicador da lei, exige-se-lhe a fundamentação de sua decisão, obrigando-o a demonstrar as razões que permearam seu espírito no momento do julgamento.

Quanto à utilização das circunstâncias judiciais como critérios de individualização, pôde-se observar:

a) o artigo 59 do Código Penal arrola uma gama de circunstâncias que, conjuntamente, envolvem autor, vítima e fato delituoso;

\footnotetext{
${ }^{6}$ Observe-se que Zaffaroni propõe um critério geral considerado a partir das finalidades da pena e da culpabilidade.
} 
b) ao arrolar a culpabilidade e elementos outros que guardam relação direta com a pessoa do agente infrator, permite alto de grau de individualização da pena;

c) como se não bastassem todos os fatores já enumerados, a referência genérica "circunstâncias" permite ao julgador considerar toda espécie de elementos acidentais relacionados com o fato;

d) consoante a natureza do delito, o juiz pode privilegiar uma circunstância em relação a outras;

e) ante a inexistência de circunstâncias legais especiais, majorantes e minorantes, a pena-base pode converter-se em pena definitiva.

Neste contexto, como forma de controle da discricionariedade judicial, adotou o Código Penal o Princípio da Legalidade, como garantia ao status libertatis e dignitatis do agente, definindo algumas circunstâncias cujo exame favorável ou desfavorável é vinculado. Por outro lado, a Constituição prescreveu, como garantia constitucional, a motivação dos provimentos jurisdicionais.

Por último, ainda ratificando o caráter instrumental das circunstâncias judiciais, observou-se sua utilização como critérios individualizadores não somente para dosar a pena-base, mas para escolher-se a modalidade da pena a ser aplicada, fixar-se o regime de cumprimento de pena e promover a substituição das penas privativas de liberdade pelas penas restritivas de direitos (art. 44), sem se lembrar da sua participação na concessão de benefícios como o Sursis (art. 77, III).

\section{REFERÊNCIAS}

BETTIOL, Giuseppe. Direito Penal. Vol. III. São Paulo: Revista dos Tribunais, 1966.

BITENCOURT, Cezar Roberto. O Arbítrio Judicial na Dosimetria Penal. Revista dos Tribunais 723 - Janeiro de 1996, p. 497 e segs.

BRUNO, Aníbal. Comentários ao Código Penal. Rio de Janeiro: Forense, v. III, . Direito Penal, Tomo III, São Paulo: Forense, 1966. 
CERNICCHIARO, Luiz Vicente; et al. Direito Penal na Constituição. 3. ed., São Paulo: Revista dos tribunais, 1995.

CRUZ, José Raimundo Gomes da. Individualização da Pena e Garantias do Acusado. Revista dos Tribunais 671 - Setembro de 1991, p. 395 e segs.

FARIA, Bento de. Código Penal Brasileiro. Rio de Janeiro: Record, v. III, 1959.

FERRAJOLI, Luigi. Derecho y Razón - teoría do garantismo penal, 2.ed. Madrid, Trotta, 1997.

FERREIRA, Gilberto. Aplicação da Pena. Rio de Janeiro: Forense, 1998.

FERRI, Enrico. Princípios de Direito Criminal. Campinas: Bookseller, 1999.

FILGUEIRAS JÚNIOR, Araujo. Codigo Criminal do Imperio do Brazil Annotado. 2. ed., Rio de Janeiro: Casa dos Editores Proprietários Eduardo \& Henrique Laemmert, 1876.

GARRAUD, R. Précis de Droit Criminel. Paris: Société Anonyme du Recueil Sirey, 1926.

GOMES, Luiz Flávio. Penas e Medidas Alternativas à Prisão. São Paulo: Revista dos Tribunais, 1999.

GOMES FILHO, Antônio Magalhães. A Garantia das decisões judiciais na Constituição de 1988. Processo Penal e Democracia. Estudos em homenagem aos 20 anos da Constituição Federal de 1988. Rio de Janeiro: Lumen Juris: 2009, p. 60.

LISZT, Franz Von. Tratado de Derecho Penal. 3. ed., Madrid: Instituto Editorial Reus.

LOPES JR., Aury. Direito Processual Penal. São Paulo: SaraivaJur, 2017.

LUISI, Luiz. Os Princípios Constitucionais Penais. Porto Alegre: Sérgio Antônio Fabris Editor, 1991.

LUNA, Everardo da Cunha. O Resultado no Direito Penal. São Paulo: Bushatsky, 1976.

. Das Penas e sua Aplicação. Revista dos Tribunais 473 - Março de 1975 - p. 265 a 269.

MARQUES, José Frederico. Tratado de Direito Penal. Campinas, SP: Bookseller, v. I, 1997. 
. Tratado de Direito Penal. Campinas, SP: Millennium, v. III, 1999.

PONTES, Ribeiro. Código Penal Brasileiro. Curitiba: Guaíra, v I. 1942.

ROCHA, Fernando Antônio N. Galvão da. A Culpabilidade como Fundamento da Responsabilidade Penal. Revista dos Tribunais v. 707, 1994, p. 276 e segs.

ROSA, Antônio José Miguel Feu. Direito Penal. Parte Geral. São Paulo: Revista dos Tribunais, 1995.

ROSA, Fábio Bittencourt da. A Pena e sua Aplicação. Revista dos Tribunais, v. 668,1991, p. 245 e segs.

SHECAIRA, Sérgio Salomão; et al. Pena e Constituição - Aspectos Relevantes para sua Aplicação e Execução. São Paulo: Revista dos Tribunais, 1995.

ZAFFARONI, Eugênio Raúl; et al. Manual de Direito Penal Brasileiro - Parte Geral - São Paulo: Revistas dos Tribunais, 1997. 